\title{
Research on the Effective Influence Radius of Hydraulic Reaming in Mining Seam
}

\author{
Li Peng ${ }^{*}, 1$, Wang $\mathrm{Kai}^{1}$, $\mathrm{Li} \mathrm{Bo}^{2}$, Jiang Yifeng ${ }^{1}$ and Gou Jianqiang ${ }^{1}$ \\ ${ }^{I}$ Faculty of Resources and Safety Engineering, China University of Mining \& Technology (Beijing), Beijing, 100083, \\ China \\ ${ }^{2}$ School of Safety Science and Engineering, Henan Polytechnic University, Jiaozuo, 454000, China
}

\begin{abstract}
In Accordance with the present situations suggesting that the construction of the gas drainage boreholes in mining seam is sufficient and the gas drainage effect in low permeability coal seams does not yield perfectly, the hydraulic reaming technology in mining seam was proposed to increase the gas drainage efficiency. Through the gas flow method, the effective influence radius of hydraulic reaming was determined and the fluid-solid coupling model of gas drainage along boreholes after hydraulic reaming was established theoretically. Following this, the changes in the laws of gas content around the boreholes in the coal seam were simulated and analyzed. The results indicated that hydraulic reaming can effectively promote the stress-relief and permeability-increase of the coal mass around the boreholes, and the coal mass around the reaming boreholes can be divided into gas flow increase zone, gas flow delay attenuation zone and fast decay zone. The effective influence radius of hydraulic reaming was $5.5 \sim 6 \mathrm{~m}$. The obtained simulation results were basically in accordance with the field investigation.
\end{abstract}

Keywords: Hydraulic reaming, effective influence radius, flow method, numerical simulation.

\section{INTRODUCTION}

In the high gassy and low permeability coal seams, there exist a series of problems corresponding to the gas drainage boreholes in the mining seam, which include the smaller effective influence range, the larger amount of construction, the longer pre-drainage time and the worst effects of gas drainage. Thus the existing gas drainage in mining seam cannot completely satisfy the urgent demands of safety production in coal mines. As a result, the major coal enterprises and related research institutes tested all kinds of technical measures for pressure relief and increased permeability, such as hydraulic fracturing, shallow hole loose explosion, deep hole pre-splitting blasting, hydraulic extrusion and hydraulic flushing. Relevant analysis showed that the former technical measures have remarkable effect in limited range or under certain conditions, the limitations of which are accordingly obvious. For instance, the induced cracks are easily compacted after hydraulic fracturing, therefore, the efficiency of seaming for the fracturing boreholes needs to be improved $[1,2]$. Due to shallow charging, the shallow hole loose explosion easily induces the coal and gas outburst [3]. Although the deep hole pre-splitting blasting provided ideal increasing permeability effect in the soft and low permeability coal seams [4], it is not likely for large scale promotion owing to the complex charging technology. Although, the operation process of hydraulic extrusion is more complicated [5], however, hydraulic flushing is more suitable for the coal seam with loose texture and a certain property of artesian flow [6].

*Address correspondence to this author at the Faculty of Resources and Safety Engineering, China University of Mining \& Technology (Beijing), Beijing, 100083, China; Tel: +8618911967389;E-mail: lipeng0718@126.com
In addition, the above measures are more suitable for locations such as the floor roadway, the working face for rock cross-cut coal uncovering or the heading face, and so on. Because these measures are usually undertaken for handling the protective rock pillar or not constructed manually, there is lack of direct and effective technical measures for pressure relief and permeability increase in mining seams, which are the key regions for gas control. Therefore, the hydraulic reaming technology in mining seam is proposed for achieving the final goals of increasing the permeability of coal seams, enlarging the valid influence range for borehole drainage and raising the gas drainage efficiency, according to the characteristics of the harder coal quality and the lower permeability, as well as for promoting the production of large number of gas drainage boreholes for the $2_{1}$ coal seam of a coal mine in Anhe coalfield.

\section{SUMMARY OF HYDRAULIC REAMING TECHNOLOGY IN MINING SEAM}

\subsection{Sketch of Test Location}

The test working face had the strike length of 1010 1018 $\mathrm{m}$ and the inclination length of $150 \mathrm{~m}$. The mining seam was $2_{1}$ coal seam located in the lower part of Shanxi group in Permian. The occurrence of coal seam was relatively stable. The dip angle of coal seam was $12 \sim 24^{\circ}$, and the thickness of coal seam was $6.6 \sim 7.4 \mathrm{~m}$, with the average of $7.0 \mathrm{~m}$. Moreover, the consistent coefficient of coal was 0.63 . Significantly, the original gas content of coal seam was 7.42 $\mathrm{m}^{3} / \mathrm{t}$ and the effective influence radius was $1.3 \sim 1.5 \mathrm{~m}$ for gas drainage of boreholes in mining seam lasted 30 days. 


\subsection{Process Overview}

The hydraulic reaming technology of mining seam isapplied to the constructed boreholes along the mining seam. The water in the storage tank is pressurized with the help of continuous pressurizing function of emulsion pump and flows sequentially through the high pressure hose, high pressure rotary water tail and high pressure pipe. Subsequently, it is ejected from the nozzles of reaming bit, and finally produces high pressure continuous water jet. Since the high pressure drill pipe and reaming bit are rotated, advanced and retreated by the mine drill, the high pressure water jet can cut and strip the coal body around the boreholes. Thus this technology can enlarge the borehole diameter, increase the exposed area of coal seam and the radial pressure-relief range of the borehole. As a result, the final aims are achieved, which are the increases in the permeability of coal seam and the gas drainage effects.

\subsection{Selection of Devices}

The drill for hydraulic reaming is the drill carriage used for deep holes in coal mine with the type of CMS1-6200/80 and the diameter of drill pipe is $73 \mathrm{~mm}$. The diameter of drill bit is $84 \mathrm{~mm}$. Furthermore, the tube connecting the drill carriage with the emulsion pump contains the wire spirallywound hose with the internal diameter of $38 \mathrm{~mm}$ and withstand voltage of $38 \mathrm{MPa}$ and the other ends of tubes are connected with the tail of drill pipe. The connections are reinforced by the quick connecters and $U$ clips. The type of nozzle is selected for $3 \Phi 1.5 \mathrm{~mm}$. Besides this, the nozzles are fixed on the special drill bit of $\Phi 75 \mathrm{~mm}$. The type of emulsion pump is BRW200/31.5, supported by the auxiliary emulsion box of FRx1000. The working water pressure of pump is $14 \sim 20 \mathrm{MPa}$. In addition, the dual function and high water pressure meter with the type of SGS is installed away from the tail of drill carriage about $5 \sim 8 \mathrm{~m}$, monitoring water pressure and flow changes. The low concentration methane sensor is fixed in the return air side of working face for monitoring the changes in gas concentration of return air flow during hydraulic reaming.

\subsection{Process Flow}

The borehole is constructed of $\Phi 84 \mathrm{~mm}$ to the depth of $85 \mathrm{~m}$ with deep hole drill carriage. The pipes are turned, followed by change in hydraulic reaming drill bit and drilling to a depth of $85 \mathrm{~m}$. The borehole is reamed outward and pipe by pipe, until the water becomes clear to a certain depth. Pipes and ream are turned to the inward position from the orifice of $20 \mathrm{~m}$, as well as controlling the output amount of coal per one meter between 0.3 ton to 0.4 ton. The gas concentration of leeward side is checked, followed by checking of the output amount of coal. The pipes are then turned and the borehole is seamed.

\section{INVESTIGATION OF EFFECTIVE INFLUENCE RADIUS FOR HYDRAULIC REAMING BY FLOW METHOD}

\subsection{Sketch of Flow Method}

The main basis for the investigation of effective influence radius for hydraulic reaming by flow method is that the drainage boreholes, along which the gas flow fluctuate noticeably during hydraulic reaming and conform to unconventional attenuation law after hydraulic reaming, located in the effective influence range. The specific reason is that the high pressure water jet impacts and crushes the coal body, and compels the mixture with coal and water to exhaust outwards. Following this, the surrounding stress of the boreholes is redistributed accordingly. Therefore, the coal mass in certain zones around boreholes follows stressrelief and the stress concentration zone is transferred to the deep coal mass. Meanwhile, the stress wave caused by the high pressure water jet produces radial compressive stress and tangential tensile stress on the coal mass in the process of propagation, which are favorable to the formation of radial cracks as well as accelerating the gas flow, and consequently, promoting the increase in gas drainage quantity.

\subsection{Layout of Boreholes}

Two groups of boreholes were arranged in the test area, and each group included one reaming borehole and two boreholes for the investigation of one group, as shown in Fig. (1). Setting the inspection boreholes in Fig. (1a) as an example, the investigation details for flow method can be expressed as follows. Before hydraulic reaming, No. 7 and 9 drainage boreholes were constructed and connected to the drainage system for extraction. Following this, No. 8 borehole for reaming was launched. The gas flow for No. 7 and 9 boreholes was continuously observed for 30 days before and after hydraulic reaming. At the same time, a group of regular drainage boreholes was arranged for comparison and analysis of gas flow for drainage boreholes in the adjacent unaffected zone for reaming. It is important to consider that the second group of inspection boreholes was similar to the former one.

\subsection{Results of the Analysis}

The changes in gas flow of every inspection borehole before and after hydraulic reaming are shown in Fig. (2). The abscissa represents the inspection date, and the ordinate represents the daily mean gas flow of the drainage boreholes. In addition, the ordinate of intersection point for vertical dotted line and flow curve represents the average data in the reaming process, shown in Fig. (2a, b).

It can be seen from Fig. (2) that in the process of reaming No. 8 borehole, the cracks in coal mass between No. 7 borehole and No. 8 borehole due to the impact action of water jet, linked with each other to a certain extent. Therefore the gas flow of No. 7 borehole drew down to $0.207 \mathrm{~m}^{3} / \mathrm{min}$ from $0.218 \mathrm{~m}^{3} / \mathrm{min}$. The probable reason is that the air flew into No. 7 borehole along the cracks through No. 8 borehole. Meanwhile, the water jet infiltrated the coal mass around No. 8 borehole, restraining gas desorption to some extent. In two or three days after reaming, gas drainage in No. 8 borehole also started. The gas flow rose higher up to $0.225 \mathrm{~m}^{3} / \mathrm{min}$ or so, owing to the stress-relief of coal mass around No. 7 borehole. As the drainage time increased, the gas flow of No. 7 borehole undulated up and down under the action of negative pressure fluctuations of the gas drainage system, but basically maintained around $0.195 \mathrm{~m}^{3} / \mathrm{min}$, 

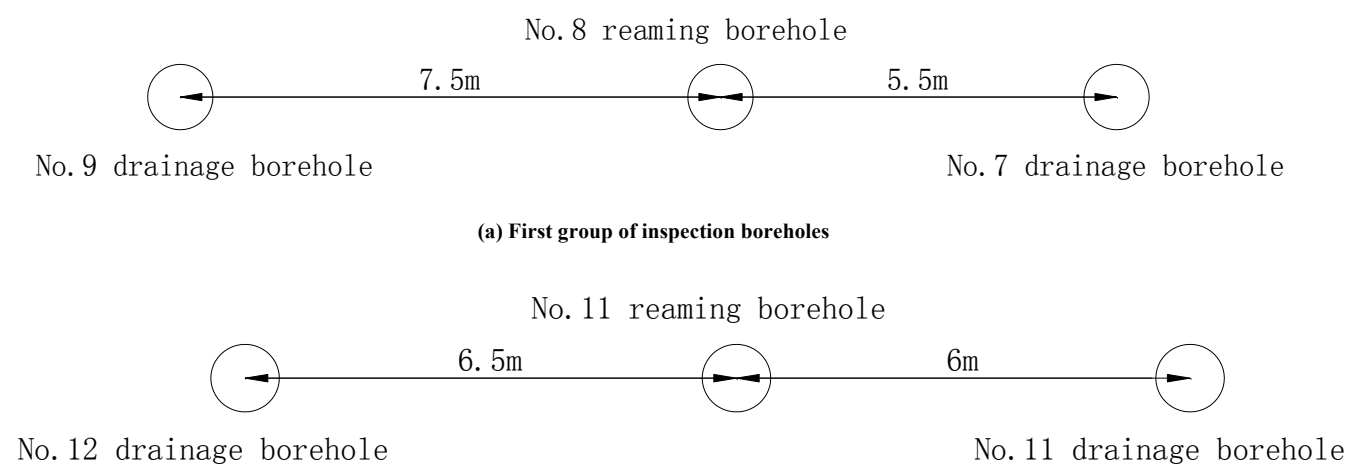

(b) Second group of inspection boreholes

Fig. (1). Layout of the boreholes for flow method.

lasting for 15 days. Following this, the gas flow in No. 7 borehole was greatly reduced, expressing most new fractures which began to be closed in the process of in-situ stress recovery. After reaming No. 8 borehole, the gas flow of No. 9 borehole initially dropped to $0.21 \mathrm{~m} \mathrm{~m}^{3} / \mathrm{min}$ but fluctuated afterwards. It became stable at around $0.19 \mathrm{~m}^{3} / \mathrm{min}$, and finally decreased gradually.

By analyzing the probable reasons, it was found that the coal mass of No. 9 borehole was located in the transition zone between the stress concentration zone and the original stress zone of No. 8 reaming borehole. The partial cracks extending to this zone began to be closed and did not appear any more, because the coal mass was under the concentrated stress. Therefore, the permeability coefficient of coal seam reduced correspondingly. In the process of reaming No. 11 borehole, the gas flow of No. 10 borehole firstly showed a slight upward trend to $0.064 \mathrm{~m}^{3} / \mathrm{min}$ from $0.06 \mathrm{~m}^{3} / \mathrm{min}$ in the day before reaming. And the gas flow gradually decreased with increase in drainage time. It can be concluded that the hydraulic reaming promoted a certain action of stress-relief and permeability-increase in the coal mass around No. 10 borehole, which soon dissipated with the completion of reaming. In addition, the coal mass of No. 10 borehole was located in the transition zone between the stress-relief zone and the stress concentration zone was produced by hydraulic reaming. However, the gas flow of No. 12 borehole firstly drew down to $0.08 \mathrm{~m}^{3} / \mathrm{min}$, and sustained for a long time and then began to decrease constantly. Compared with No. 9 borehole, the gas flow attenuation coefficient was much lower, indicating that the coal mass of No. 12 borehole was located in the stress concentration zone induced by the hydraulic reaming, therefore, the gas flow decreased but was not like the rapid decline of regular gas drainage boreholes. In addition, the total gas drainage amount of one month for the investigation boreholes around the reaming ones was 2.17 times than one of the adjacent regular drainage boreholes unaffected by hydraulic reaming. In addition, the average gas flow attenuation coefficient was only 0.31 of regular drainage boreholes. This also proved the validity and reliability of hydraulic reaming technology.

In summary, the coal mass around the reaming borehole can be divided into gas flow increase zone, gas flow delay attenuation zone and gas flow fast decay zone from the wall of borehole to the depths of coal mass, according to the change in gas flow. In the gas flow increase zone, the stress was relieved and the permeability increased for the coal mass due to the impaction of water jet, and the gas flow also increased accordingly. In the gas flow delay attenuation zone, the partial cracks extending to this zone started to be closed under the concentrated stress and the gas flow decreased consequently. But the attenuation coefficient of gas flow decreased due to the local action of stress-relief and permeability-increase. In gas flow fast decay zone, as the coal mass was not affected by the impaction of water jet, the gas flow followed the rapid attenuation rule of the low permeability coal seam. Thus, it can be concluded that the coal mass within 6 meters of reaming boreholes belongs to gas flow increase zone, which is an effective influence range of hydraulic reaming. And the gas flow delay attenuation zone included the coal mass in the range within $6 \sim 7.5 \mathrm{~m}$ around the reaming boreholes. Furthermore, the gas flow fast decay zone contained coal mass about $7.5 \mathrm{~m}$ outside of reaming boreholes, which is also the unaffected range for hydraulic reaming. In other words word, the effective influence radius of hydraulic reaming in mining seam can be determined as $5.5 \sim 6 \mathrm{~m}$.

\section{NUMERICAL SIMULATION}

In order to verify the validity of the flow method, the fluidsolid coupling numerical model of gas drainage for in-seam boreholes after hydraulic reaming was built for discussing the changed rules of gas content in coal mass around the drainage boreholes after reaming. Moreover, the changed rules were compared and analyzed with the measured data for more accurately determining the effective influence radius of hydraulic reaming. Therefore, initially, the following hypothesis was made, including: I. The coal mass is comprised of porous medium and saturated by methane. II. The coal mass is a homogeneous isotropic elastic medium. III. The effects of the changes in temperature and gas adsorption and desorption on coal deformation and gas seepage process have not been taken into consideration.

\subsection{Mathematical Model}

\subsubsection{Governing Equations of Coal Deformation}

The skeleton deformation of coal mass containing gas is widely expected to obey Terzaghi's effective stress principle [7-9]. According to the law of conservation of momentum, the equation of stress equilibrium is expressed with effective stress and pore pressure as 
$\left(\sigma_{i j}^{\prime}\right)_{, j}+\left(\alpha p \delta_{i j}\right)_{, j}+F_{i}=0$

(a) No. 7 borehole

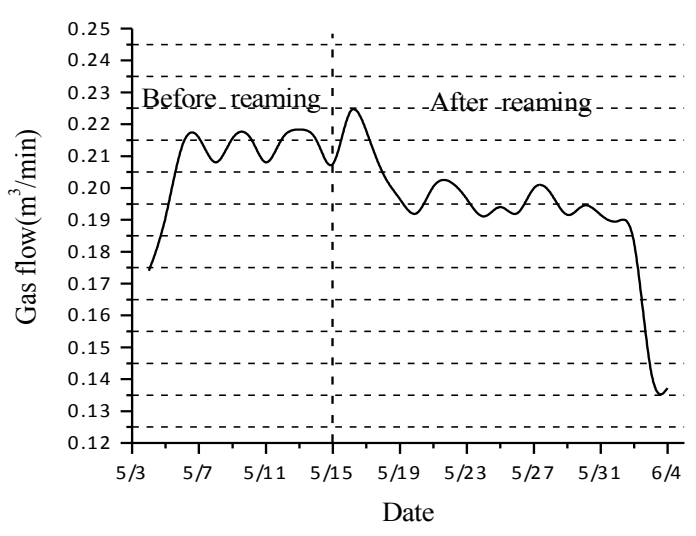

(b) No. 9 borehole

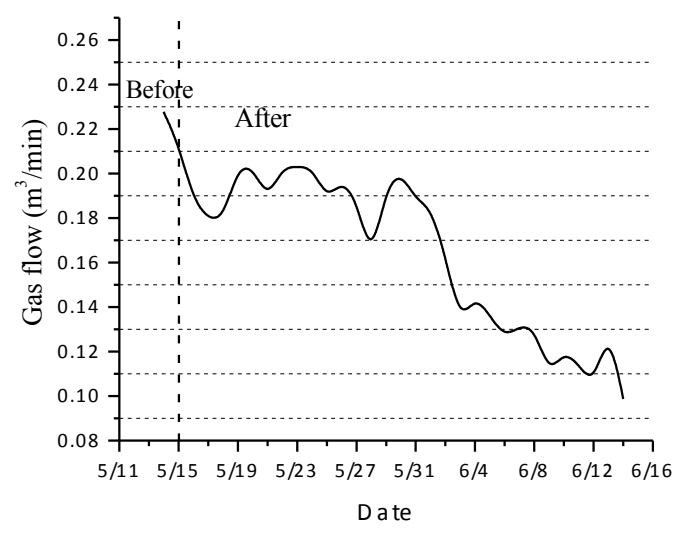

(c) No. 10 borehole

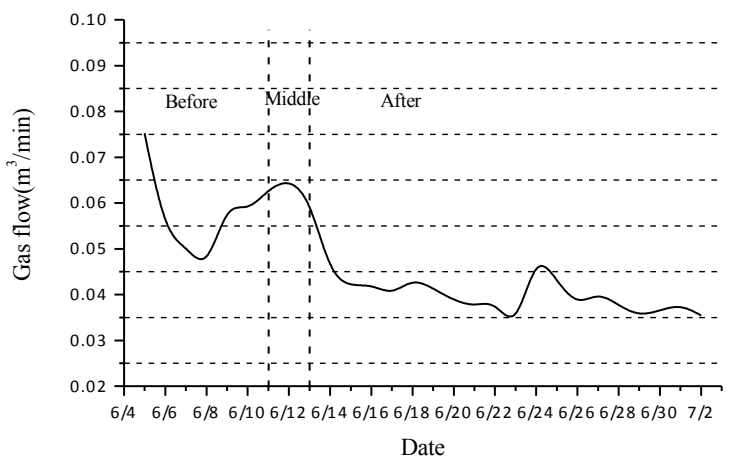

(d) No. 12 borehole

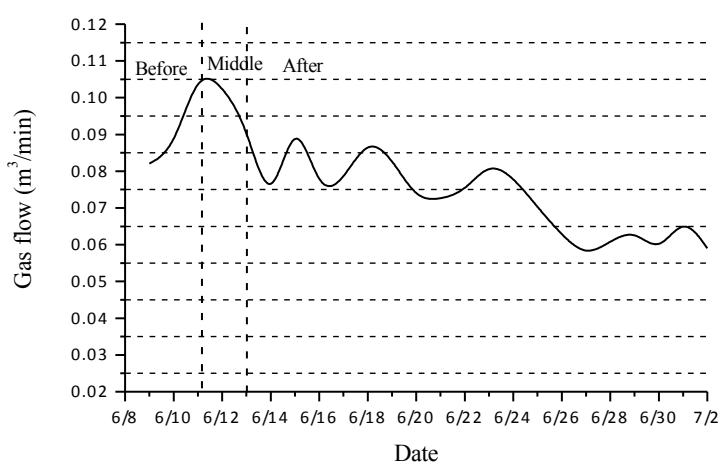

Fig. (2). Change rules of gas flow along the inspection boreholes. in which $\sigma_{i j}$ ' is the effective stress tensor of coal mass containing gas $(\mathrm{Pa}, i, j=1,2,3), \alpha$ is Biot's coefficient $\left(=-K / K_{s}\right), K$ is the bulk modulus of coal mass containing gas $(\mathrm{Pa}), K_{s}$ is the effective bulk modulus of coal grains $(\mathrm{Pa}), \delta_{i j}$ is the Kronecker delta as 1 for $i=j$ and 0 for $\mathrm{i} \neq \mathrm{j}, \mathrm{p}$ is the pore pressure $(\mathrm{Pa})$, and $F_{\mathrm{i}}$ is the body force $(\mathrm{Pa})$.

According to the continuity conditions of deformation, the strain component of coal mass containing gas $\varepsilon_{i j}$ is defined as

$\varepsilon_{i j}=\frac{1}{2}\left(u_{i, j}+u_{j, i}\right)$

Where, $u_{i, j}$ and $u_{j, i}$ are the displacement components of coal mass containing gas.

The coal deformation is assumed to be linear elastic, and the deformation constitutive equation of coal mass containing gas can be expressed as

$$
\sigma_{i j}=2 G \varepsilon_{i j}+\frac{2 G v}{1-2 v} \varepsilon_{k k} \delta_{i j}+\alpha p \delta_{i j}
$$

Where, $\sigma_{i j}$ is the total stress tensor of coal mass containing gas $(\mathrm{Pa}), G$ is the shear modulus of coal mass containing gas $(\mathrm{Pa})$, and $v$ is the Poisson's ratio of coal mass containing gas.

Substituting Eq. (2) and (3) into Eq. (1) yields the deformation governing equation of coal mass containing gas as

$$
G u_{i, j j}+\frac{G}{1-2 v} u_{j, j i}+\alpha p_{, i}+F_{i}=0
$$

\subsubsection{Dynamic Evolution Equations of Porosity and Permeability}

Based on the definition of porosity and only considering the effects of changes in gas pressure on the skeleton deformation of coal mass, the dynamic evolution equation of porosity in coal mass containing gas can be expressed as $[10,11]$

$\varphi=1-\frac{1-\varphi_{0}}{1+\varepsilon_{v}}\left(1-\frac{\Delta p}{K_{s}}\right)$

Where $\varphi$ is the porosity of coal mass containing gas, and $\varphi_{0}$ is the initial porosity, $\varepsilon_{v}$ is the volumetric strain of coal mass containing gas, $\Delta p$ denotes the changes in gas pressure $\left(=p-p_{0}\right)$, and $p_{0}$ is the initial gas pressure $(\mathrm{Pa})$.

Based on the Kozeny-Carman equation as $k / k 0=\left(\varphi / \varphi_{0}\right)^{3}$, the dynamic evolution equation of permeability can be expressed as

$k=\frac{k_{0}}{1+\varepsilon_{v}}\left[1+\frac{\varepsilon_{v}+\Delta p\left(1-\varphi_{0}\right) / K_{s}}{\varphi_{0}}\right]^{3}$

Where $k$ is the permeability of coal mass containing gas $\left(\mathrm{m}^{2}\right)$, and $k_{0}$ is the initial permeability $\left(\mathrm{m}^{2}\right)$.

\subsubsection{Governing Equations of Seepage Field}

According to the mass conservation law, the gas propagation equation of coal seam can be defined as

$\frac{\partial m}{\partial t}+\nabla \cdot\left(\rho_{g} \cdot v_{g}\right)=Q_{s}$

Where $m$ is the gas content $\left(\mathrm{kg} / \mathrm{m}^{3}\right)$, including two parts as free gas content $m_{g}$ and adsorbed gas content $m_{a}, t$ is the time (s), $\rho_{g}$ is the density of gas $\left(\mathrm{kg} / \mathrm{m}^{3}\right), v_{g}$ is the gas seepage velocity $(\mathrm{m} / \mathrm{s})$, and $Q_{s}$ is a source term $\left(\mathrm{kg} /\left(\mathrm{m}^{3} \cdot \mathrm{s}\right)\right)$. 
Based on the ideal gas equation of state [12] and the Langmuir's isothermal adsorption equation [13], the gas content can be expressed as

$m=\frac{M_{g} \varphi p}{R T}+\frac{a b c p \rho_{0}}{1+b p}$

Where $M_{\mathrm{g}}$ is the molar mass of gas $(=16 \mathrm{~kg} / \mathrm{kmol}), R$ is the universal gas constant $(=8.314 \mathrm{~kJ} /(\mathrm{kmol} \cdot \mathrm{K})), \quad T$ is the temperature (K), $a$ is the limited adsorption quantity unit mass of coal $\left(\mathrm{m}^{3} / \mathrm{kg}\right), b$ is the adsorption constant of coal $\left(\mathrm{MPa}^{-1}\right), c$ is the correction parameter of coal $\left(=\frac{\rho_{\mathrm{c}}(100-A-M)}{100(1+0.31 M)}, \mathrm{kg} / \mathrm{m}^{3}\right)$, in which $\rho_{\mathrm{c}}$ is the density of coal $\left(\mathrm{kg} / \mathrm{m}^{3}\right), A$ is the ash content of coal (\%), $M$ is the moisture of coal (\%), $p_{\mathrm{s}}$ is the standard atmospheric pressure $(\mathrm{Pa})$, and $\rho_{0}$ is the gas density under the standard atmospheric pressure $\left(\mathrm{kg} / \mathrm{m}^{3}\right)$.

As the gas propagation in coal seam is assumed to obey the Darcy's law, and meanwhile considering the influence of Klinkenberg's effect, the gas seepage velocity can be expressed as [14]

$v_{g}=-\frac{k}{\mu}\left(1+\frac{m_{k}}{p}\right) \cdot \nabla p$

Where $\mu$ is the dynamic viscosity coefficient of gas $\left(=1.08 \times 10^{-6} \mathrm{~Pa} \cdot \mathrm{s}\right)$, and $m_{k}$ is the Klinkenberg's coefficient $(\mathrm{Pa})$.

According to the hypothesis of III and only considering the effect of gas pressure and stress with strain on porosity, the changed law of the porosity of coal mas containing gas can be expressed as [14]

$\frac{\partial \varphi}{\partial t}=(1-\varphi)\left(\frac{\partial \varepsilon_{v}}{\partial t}+\frac{1}{K_{s}} \frac{\partial p}{\partial t}\right)$

Substituting Eqs. (8) (10) into Eq. (7), the governing equation of the seepage field can be rewritten as

$$
\begin{aligned}
& 2 \alpha p \frac{\partial \varepsilon_{v}}{\partial t}+2\left[\frac{a b c p_{s}}{(1+b p)^{2}}+\frac{p(1-\varphi)}{K_{s}}+\varphi\right] \frac{\partial p}{\partial t} \\
& -\nabla \cdot\left[\frac{k}{\mu}\left(1+\frac{m_{k}}{p}\right) \nabla p^{2}\right]=0
\end{aligned}
$$

\subsection{Geometric Model and Physical Parameters}

According to the basic hypothesis and experimental data, the simulation analysis of hydraulic reaming can be simply calculated by the two-dimensional plane strain mode. The height of computational domain was $7 \mathrm{~m}$, with a corresponding length of $100 \mathrm{~m}$. The corresponding locations of boreholes are shown in Fig. (1). The reaming borehole was located in the middle of the domain and the inspection boreholes were located on the left and right sides of the reaming borehole. Besides, the reaming boreholes' radius was converted into per meter of coal output as $0.4 \mathrm{t}$, owing to the boreholes after reaming was considered for the cylinder. Therefore, the radius of No.8 and 11 boreholes was $0.304 \mathrm{~m}$, and the radius of other drainage boreholes was $0.042 \mathrm{~m}$. The physical parameters required for the calculation are listed as Table $\mathbf{1}$.

\subsection{Initial Conditions and Boundary Conditions}

Initial conditions: The initial gas pressure of coal seam $p(x, y, 0)$ was equal to $0.37 \mathrm{MPa}$, and the initial displacement of stress filed $u_{i}$ was equal to $0(i=1,2)$.

Boundary conditions: I. Stress boundary conditions: The top boundary of coal seam endured the weight of overburdened rock stratum, with a stress of $12.9 \mathrm{MPa}$ and the weight of coal mass was also considered. II. Displacement boundary conditions: The vertical bottom of the model was fixed, and the horizontal displacement of the left boundary and the right one was limited as 0. III. Boundary condition of seepage filed: The outside boundaries of the model were air-tight, and the wall of boreholes served as the boundary for drainage

$p(x, y, t)=p_{d}, x^{2}+y^{2}=r^{2}$

Where $p_{d}$ is the negative gas drainage according to the measured value of $-39 \mathrm{kPa}$.

\section{ANALYSIS OF THE SIMULATION RESULTS}

The distribution of residual gas content of the coal mass around the reaming boreholes after extracting for 30 and 40 days respectively, is shown in Fig. (3). It can be seen from Fig. (3a) that, while No. 8 borehole was extracted for 30 days after hydraulic reaming, the maximum residual gas content

Table 1. Physical parameters of coal seam containing gas.

\begin{tabular}{|c|c|c|c|}
\hline Parameters & Values & Parameters & Values \\
\hline \hline Elastic modulus $E(\mathrm{MPa})$ & 2460 & Original gas content $\left(\mathrm{m}^{3} / \mathrm{t}\right)$ & 7.42 \\
\hline Poisson's ration $v$ & 0.3 & Dynamic viscosity of gas $(\mathrm{Pa} \cdot \mathrm{s})$ & $1.08 \times 10^{-6}$ \\
\hline Compression strength $(\mathrm{MPa})$ & 7.0 & Compression coefficient of gas & 1.0 \\
\hline Internal friction angle $\left({ }^{\circ}\right)$ & 33.4 & Adsorption constant of coal $a\left(\mathrm{~m}^{3} / \mathrm{t}\right)$ & 38.389 \\
\hline Density of coal $\left(\mathrm{kg} / \mathrm{m}^{3}\right)$ & 1400 & Moisture content of coal $M(\%)$ & 0.582 \\
\hline Initial porosity $(\%)$ & 6.82 & Ash content of coal $A(\%)$ & 0.59 \\
\hline Initial permeability of coal seam $\left(\mathrm{m}^{2}\right)$ & $5.52 \times 10^{-17}$ & Buried depth of coal seam $(\mathrm{m})$ & 14.03 \\
\hline Original gas pressure $(\mathrm{MPa})$ & 0.37 & $\left.\mathrm{MPa}^{-1}\right)$ & 490 \\
\hline
\end{tabular}


of coal seam between No.8 and 9 boreholes was $5.82 \mathrm{~m}^{3} / \mathrm{t}$, reduced by $20.59 \%$ than the original one. In addition, the maximum residual gas content between No.7 and 8 boreholes was $5.395 \mathrm{~m}^{3} / \mathrm{t}$, reduced by $27.29 \%$ than the original one. While the boreholes were extracted for 45 days,

the maximum residual gas content between No.8 and 9 boreholes was $5.403 \mathrm{~m}^{3} / \mathrm{t}$, reduced by $27.18 \%$. The maximum residual gas content between No.7 and 8 boreholes was $4.943 \mathrm{~m}^{3} / \mathrm{t}$, reduced by $33.38 \%$ than the original one. In addition, the residual gas content of coal seam in the middle of No.8 and 9 borehole was just $5.3 \mathrm{~m}^{3} / \mathrm{t}$, similar to the test value of $5.32 \mathrm{~m}^{3} / \mathrm{t}$, verifying the accuracy of the numerical model. From the declining degree of gas content, it was found that the residual gas content of the inspection borehole away from the reaming borehole to 5.5 $\mathrm{m}$, was reduced by $30 \%$ or more after the gas extraction of
45 days. It also can be seen from Fig. (3b) that, while No.11 borehole was extracted for 30 days after hydraulic reaming, the maximum residual gas content of coal seam between No. 10 and 11 boreholes was $5.257 \mathrm{~m}^{3} / \mathrm{t}$, reduced by $29.15 \%$ than the original one and the maximum residual gas content between No.11 and 12 boreholes was $5.655 \mathrm{~m}^{3} / \mathrm{t}$, reduced by $23.79 \%$ than the original one. While the boreholes extracted for 45 days, the maximum residual gas content between No.10 and 11 boreholes was $5.057 \mathrm{~m}^{3} / \mathrm{t}$, reduced by $31.85 \%$, and the maximum residual gas content between No.11 and 12 boreholes was $5.174 \mathrm{~m}^{3} / \mathrm{t}$, reduced by $30.27 \%$ than the original one. Moreover, by analyzing the declining degree of gas content, it was found that the residual gas content of the inspection borehole away from the reaming borehole to $6 \mathrm{~m}$, was reduced by $30 \%$ or more after the gas extraction of 45 days. But the residual gas content of the inspection borehole away from the

(a) First group of inspection boreholes

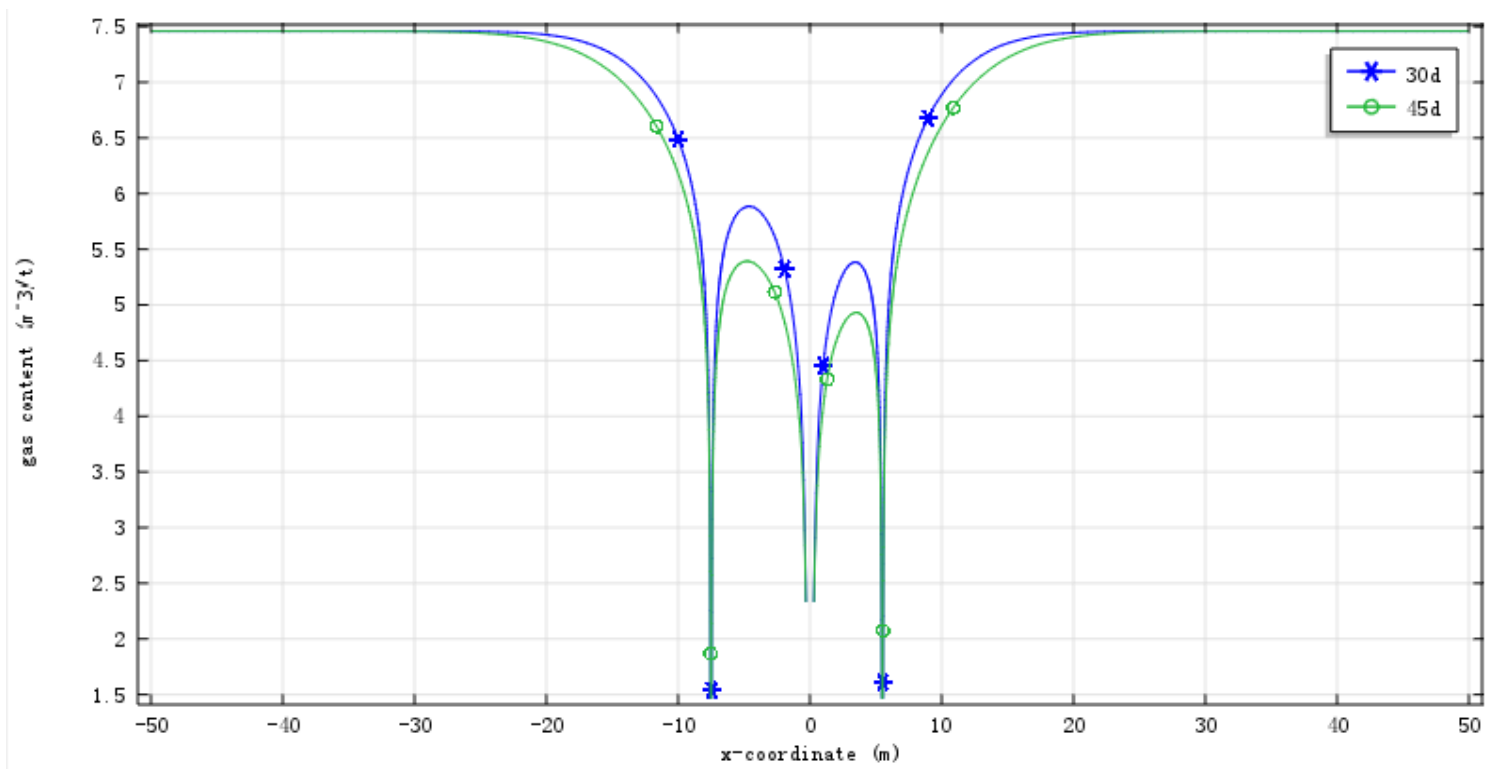

(b) Second group of inspection boreholes

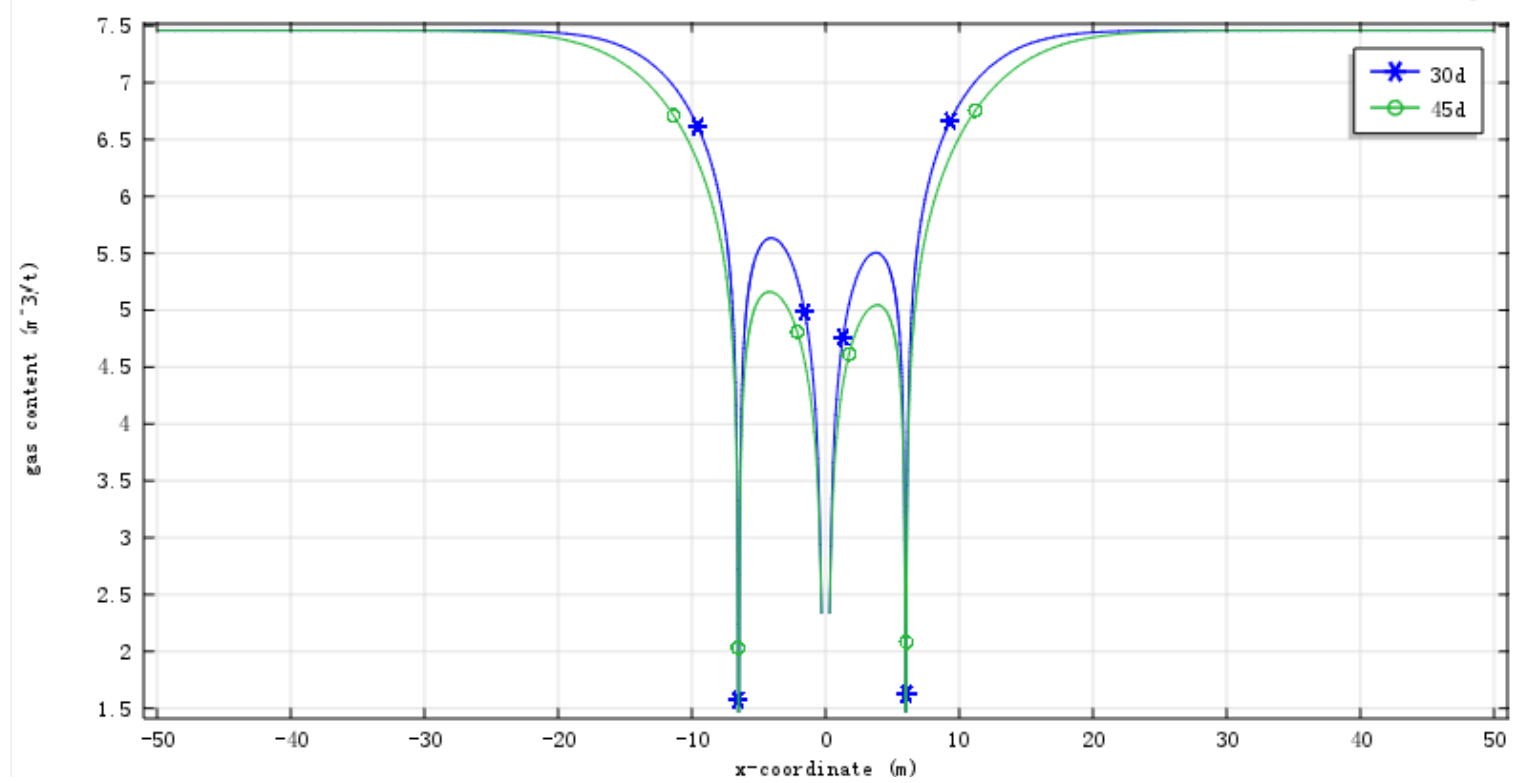

Fig. (3). Distribution of residual gas content after different drainage time. 
reaming borehole to $6.5 \mathrm{~m}$, barely reduced by $30 \%$ after the gas extraction of 45 days. According to "Provisional regulations for the gas drainage up to the standards of coal mine" and the actual gas drainage conditions for this coal mine, the gas content of coal mass among the boreholes with extraction of 45 days after hydraulic reaming, was reduced by $30 \%$, which is regarded as critical investigation value of effective influence radius of hydraulic reaming. Thus the effective influence radius of hydraulic reaming was5.5 6 $\mathrm{m}$ and not beyond $6.5 \mathrm{~m}$, in accordance with the field investigation results.

\section{CONCLUSION}

I. According to the following characteristics that the construction of the gas drainage boreholes in mining seam is large and the gas drainage effect in low permeability coal seams does not yield perfectly, the hydraulic reaming technology in mining seam was proposed correspondingly. Moreover, through the field test, the technical parameters and the process flow of hydraulic reaming were determined.

II. Based on the changes in gas flow of the inspection boreholes before and after hydraulic reaming, the coal mass around the reaming borehole can be divided into gas flow increase zone, gas flow delay attenuation zone and gas flow fast decay zone from the wall of borehole to the depths of coal mass and the coal mass within 6 meters of reaming boreholes belongs to gas flow increase zone, which is an effective influence range of hydraulic reaming. The gas flow delay attenuation zone included the coal mass in the range within $6 \sim 7.5 \mathrm{~m}$ around the reaming boreholes. Furthermore, the gas flow fast decay zone contained the coal mass about $7.5 \mathrm{~m}$ outside of reaming boreholes, which is also the unaffected range for hydraulic reaming.

III. The fluid-solid coupling model of gas drainage along boreholes after hydraulic reaming was established and the distribution of gas content around the boreholes in the coal seam after hydraulic reaming was carried out. Finally, the effective influence radius of hydraulic reaming was determined as $5.5 \sim 6 \mathrm{~m}$, not beyond $6.5 \mathrm{~m}$. The reliability of flow method and the effectiveness of hydraulic reaming technology were verified by the simulation results.

\section{CONFLICT OF INTEREST}

The authors confirm that this article content has no conflict of interest.

\section{ACKNOWLEDGEMENTS}

This study was supported by National Natural Science Foundation of China $(51474219,51174212,51304213)$, the Special Research Foundation for Doctorate Disciplines in Universities of China (20120023110006), State Key Laboratory for Coal Resources and Safe Mining, China University of Mining \&Technology (SKLCRSM13KFB08), Henan Key Laboratory of Biogenic Traces \& Sedimentary Minerals (No. OTMP1410), and China Postdoctoral Science Foundation (No. 2014M552003).

\section{REFERENCES}

[1] Ni, G.H.; Lin, B.Q.; Zhai, C.; Li, X.Z.; Li, Q.G. Borehole sealed parameter measurement and analysis of pulsating hydraulic fracturing. J. China Univ. Min. Technol., 2013, 42(2), 177-182.

[2] Lin, B.Q.; Meng, J.; Ning, J.; Zhang, M.B.; Li, Q.G.; Liu, Y. Research on dynamic characteristics of hydraulic fracturing in coal body containing gas. Caikuang yu Anquan Gongcheng Xuebao, 2012, 29(1), 106-110.

[3] Liu, J.; Liu, Z.G.; Gao, K.; Jiang, E.L. Application of deep borehole blasting to top-coal pre-weakening and gas extraction in fully mechanized caving. Yanshilixue Yu Gongcheng Xuebao, 2014, 33(Suppl.1), 3361-3367.

[4] Gong, M.; Huang, Y.; Wang, D.S.; Li, D.H. Numerical simulation on mechanical characteristics of deep-hole presplitting blasting in soft coal bed. Yanshilixue Yu Gongcheng Xuebao, 2008, 27(8), 1674-1681.

[5] Liu, M.J.; Kong, L.A.; Hao, F.C.; Xin, X.P.; Wei, G.Y.; Liu, Y.W. Application of hydraulic flushing technology in severe outburst coal. Meitan Xuebao, 2005, 30(4), 451-454.

[6] Wang, K.; Li, B.; Wei, J.P.; Li, P. Change regulation of coal seam permeability around hydraulic flushing borehole. Caikuang yu Anquan Gongcheng Xuebao, 2013, 30(5), 778-784.

[7] Li, H.H.; Rutqvist, J. A new coal-permeability model: internal swelling stress and fracture-matrix interaction. Transp. Porous Media, 2010, 82(1), 157-171.

[8] Zhu, W.C.; Wei, C.H.; Liu, J.; Qu, H.Y.; Elsworth, D. A model of coalgas interaction under variable temperatures. Int. J. Coal Geol., 2011, 86(2-3), 213-221.

[9] Lu, Y.Y.; Jia, Y.J.; Ge, Z.L.; Xia, B.W. Coupled fluid-solid model of coal bed methane and its application after slotting by high-pressure water jet. J. China Univ. Min. Technol., 2014, 43(1), 23-29.

[10] Ran, Q.Q.; Li, S.L. Study on dynamic model of reservoir parameters in the coupling simulation of multiphase flow and reservoir deformation. Shiyou Kan Tan Yu Kai Fa, 1997, 24(3), 61-65.

[11] Hu, G.Z.; Xu, J.L.; Wang, H.T.; Jin, Z.Y.; Wu, R.L. Research on a dynamically coupled deformation and gas flow model applid to lowpermeability coal. J. China Univ. Min. Technol., 2011, 40(1), 1-6.

[12] Saghafi, A.; Faiz, M.; Roberts, D. $\mathrm{CO}_{2}$ storage and gas diffusivity properties of coals from Sydney basin, Australia. Int. J. Coal Geol., 2007, 70(1-3), 240-254.

[13] Rudzinski, W.; Panczyk, T. Phenomenological kinetics of real gasadsorption-systems: isothermal adsorption. J. Non-Equilib. Thermodyn., 2002, 27(2), 149-204.

[14] Liang, B.; Yuan, X.P.; Sun, W.J. Seepage coupling model of in-seam gas extraction and its applications. J. China Univ. Min. Technol., 2014, 43(2), 208-213. 